\title{
REALIZAÇÃO DE SONHOS PARA CRIANÇAS EM CUIDADOS PALIATIVOS INTENSIVOS: RELATO DE EXPERIÊNCIA
}

\section{Pôster}

Autores deste trabalho:

Maíra Lilian Recchia Santa Cruz: Hospital Infantil Sabará

Área do Trabalho: Pediatria

Data da submissão:09/08/2018 às 15:51

\section{Justificativa}

A Organização Mundial da Saúde (OMS) definiu que os cuidados paliativos representam a assistência promovida por uma equipe multidisciplinar, com o objetivo da melhora da qualidade de vida do paciente e seus familiares diante de uma doença que ameace a vida, mediante a prevenção e alivio do sofrimento, da identificação precoce, avaliação impecável e tratamento da dor e demais sintomas físicos, sociais, psicológicos e espirituais" (1). Entende-se que os cuidados paliativos oferecem um sistema de apoio para ajudar os pacientes e familiares a viverem ativamente o quanto possível até a morte (2). Compreendendo a importância do relacionamento entre equipe multidisciplinar, pacientes e respectivos familiares é que surgiu a proposta de realização de um projeto de realização de sonhos de pacientes pediátricos em um hospital infantil pediátrico da capital paulista.

\section{Objetivo(s)}

Relatar a experiência da implantação do projeto de realização de sonhos desde a sua implantação até o presente momento.

\section{Método(s)}

Trata-se de um relato de experiência elencando os resultados obtidos com a proposta da realização de sonhos para pacientes em cuidados paliativos internados em unidades de terapia intensiva pediátrica.

\section{Resultado(s)}

O projeto de realização de sonhos foi instituído em 2018 com ações em parceria entre o grupo de cuidados paliativos institucional e o setor CHILD LIFE. Desde sua implantação duas crianças foram contempladas pelo projeto. Os sonhos realizados incluíram desde um bolo de aniversário até a visita do corpo de bombeiros no leito do paciente a beira da morte e contou com o envolvimento e atuação da equipe multidisciplinar.

\section{Conclusão (ões)}

A realização de sonhos em um período crítico de vida, possibilitou a pacientes em cuidados paliativos e aos seus familiares um cuidado singular e capaz de satisfazer, por vezes, o último desejo manifesto em vida, medida capaz de transpor a prática meramente assistencial com esforços voltados à assistência humanizada. 